\title{
A paired-sibling analysis of the Xbal polymorphism in the muscle glycogen synthase gene
}

\author{
M. Orho-Melander ${ }^{1}$, P. Almgren ${ }^{1}$, T. Kanninen ${ }^{1}$, C. Forsblom ${ }^{2}$, L.C. Groop ${ }^{1}$ \\ ${ }^{1}$ The Department of Endocrinology, Wallenberg Laboratory, Malmö University Hospital, University of Lund, Malmö, Sweden \\ ${ }^{2}$ The Department of Medicine, University of Helsinki, Helsinki, Finland
}

\section{Abstract}

Aims/hypothesis. We have previously shown an association between a XbaI polymorphism in the muscle glycogen synthase gene (GYS1) and both Type II (non-insulin-dependent) diabetes mellitus and hypertension. Association studies are, however, hampered by the selection of the control group. To circumvent these problems we addressed the same question using a novel genotype discordant paired-sibling approach.

Methods. We identified 122 sex-matched sib-pairs discordant for the Xba1 polymorphism among a new set of 743 Finnish subjects from 227 families with Type II diabetes and paired analyses were done by McNemar test of symmetry and by permutation tests. Results. Paired analysis showed that siblings with the A2 variant had more hypertension $(p=0.0067)$, obesity $(p=0.033)$ and microalbuminuria $(p=0.031)$ but not significantly more Type II diabetes $(p=0.27)$ than siblings with the A1 variant. Siblings with the A2 variant were more often treated by insulin $(p=0.050) \quad$ or anti-hypertensive medication $(p=0.0060)$ or both. Diabetic A2 variant carriers had higher triglyceride $(p=0.023)$ and lower HDL cholesterol $(p=0.0059)$ concentrations and an earlier age at onset of diabetes $(p=0.022)$ than diabetic siblings with the A1 variant. In non-diabetic sib-pairs the presence of the A2 variant was associated with higher diastolic $(p=0.0014)$ blood pressure. Finally, the allele frequency of the XbaI polymorphism differed between 216 randomly chosen unrelated Type II diabetic patients and 115 unrelated healthy control spouses without a family history of Type II diabetes (12.7 vs. $6.5 \%, p=0.013)$.

Conclusion/interpretation. The A2 allele of the XbaI polymorphism in the GYS1 confers an increased susceptibility to different features of the metabolic syndrome and Type II diabetes. [Diabetologia (1999) 42: 1138-1145]

Keywords Muscle glycogen synthase gene, GYS1, paired-sibling analysis, Type II diabetes, hypertension, metabolic syndrome, chromosome 19, candidate gene, myocardial infarction, microalbuminuria.
Impaired insulin-stimulated peripheral glucose uptake represents an early metabolic defect in the devel-

Received: 22 January 1999 and in final revised form: 21 April 1999

Corresponding author: M. Orho-Melander, PhD, Department of Endocrinology, Wallenberg Laboratory, 3rd floor, University of Lund, Malmö University Hospital, entrance 46, 20502 Malmö, Sweden.

Abbreviations: GYS1, Muscle glycogen synthase gene; OSD, observed sum of differences; TDT, transmission disequilibrium test; HOMA, homeostasis model assessment opment of Type II ( non-insulin-dependent) diabetes mellitus [1,2] and results primarily from impaired non-oxidative glucose metabolism, i.e. glycogen synthesis in skeletal muscle [1,3]. The impairment in insulin-stimulated glycogen synthesis has been associated with impaired activation of glycogen synthase [4-6]. Deterioration in insulin-stimulated glycogen synthase activity has been consistently shown in normoglycaemic first-degree relatives of patients with Type II diabetes [4,5] and in cultured fibroblasts [7] and myoblasts [8] from patients with Type II diabetes suggesting that impaired glycogen synthase activity in the skeletal 
muscle could be an inherited defect in patients with Type II diabetes. Furthermore, exercise restored glucose transport into the cell in insulin-resistant subjects to normal without overcoming the defect in glycogen synthesis [9]. Increased glycogen synthase activity in the skeletal muscle of transgenic mice overexpressing this synthase led to an increase in muscle glycogen accumulation without any change in glucose transport [10], which supports an active role for it in determining glycogen accumulation. On the basis of these data, the muscle glycogen synthase gene (GYS1) has been considered an important candidate gene for inherited skeletal muscle insulin resistance. In support of this hypothesis, an association between markers in GYS1 on chromosome 19q13.3 [11] and Type II diabetes has been described in Finnish, French, Japanese and Pima Indian populations [12-16].

The Finnish Type II diabetic patients with the A2 allele of the XbaI polymorphism in intron 14 of the GYS1 were more insulin resistant and had high blood pressure when compared with patients with two A1 alleles [12]. Furthermore, in non-diabetic subjects, this polymorphism was associated with hypertension in subjects with a family history of Type II diabetes [17]. Several studies have, however failed to replicate these findings [18-20]. Population-based association studies are prone to bias due to selection of genetically different control groups [21, 22]. Subjects in casecontrol studies can also vary considerably in other susceptibility genes and risk factors. Therefore, intra-family association studies like the transmission disequilibrium test (TDT) have been proposed to circumvent the problem [22]. The TDT requires access to DNA from parents, which is not always possible for late-onset diseases like Type II diabetes and hypertension. An alternative powerful approach is to compare phenotypic variables between siblings discordant for a genetic variant [23]. This approach was successfully used to identify an association between a Trp64Arg variant in the $\beta 3$-adrenergic receptor gene and features of the insulin resistance syndrome and obesity $[24,25]$. Siblings share about $50 \%$ of their genetic background as well as the common familial environment which possibly allows the detection of minor differences. We therefore tested the hypothesis put forward in the association studies, that the XbaI polymorphism is associated with features of the metabolic syndrome [26] in a paired-sibling analysis comprising 122 sib-pairs from a new family collection in Finland.

\section{Materials and methods}

Subjects. Siblings for the genotype-discordant sib-pair association study and the Type II diabetic patients for the case-control association study were identified from a sample of 743 subjects (323 men, 420 women) from 227 families belonging to the Botnia-II study of Type II diabetes families in Finland. Families with at least two subjects with Type II diabetes from 10 centres around Finland were invited to participate during 1995-1997. The Botnia-II family cohort was an extension of the earlier Botnia-I family cohort in western Finland with the aim of identifying genes that increase susceptibility to Type II diabetes [27]. The 743 subjects were chosen for genotyping of the XbaI polymorphism in the GYS1 gene from the whole Botnia-II Type II diabetes family cohort (1797 subjects from 345 families). To be included in genotyping a subject had to have at least one sibling of similar sex with available DNA. Siblings with a diagnosis of Type I (insulin-dependent) diabetes mellitus or aged under 30 years were excluded.

In total, 122 sib-pairs matched for sex who were discordant for the XbaI polymorphism were identified including 177 unique subjects [93 subjects with the A2 variant (genotypes $\mathrm{A} 1 \mathrm{~A} 2$ and $\mathrm{A} 2 \mathrm{~A} 2$ ) and 84 with the A1 variant (genotype A1A1) from 58 sibships (55 families)]. Clinical characteristics of the 177 subjects are shown in Table 1 . Of the sibships 8 had both male and female pairs giving a total number of sibships of 65 . There were 33 sibships with 2, 21 sibships with 3, 8 with 4,2 with 5 and one sibships with 6 subjects.

To obtain an estimate of allele frequencies, a random sample of 216 unrelated Type II diabetic patients (93 men / 123 women, age $59.3 \pm 13.5$ years, BMI $\left.29.5 \pm 4.7 \mathrm{~kg} / \mathrm{m}^{2}\right)$ were compared with 115 unrelated healthy spouses ( 56 men / 59 women, age $59.3 \pm 9.9$ years, BMI $\left.26.6 \pm 4.2 \mathrm{~kg} / \mathrm{m}^{2}\right)$. One diabetic patient per family was randomly chosen among 743 siblings from 216 families with diabetic siblings. The 115 spouses represent all the spouses from the Botnia-II cohort that were older than 40 years, had normal glucose tolerance and did not have a family history of diabetes. There were 45 Type II diabetic patients (15 men and 30 women) included in both the genotype discordant sib-pair and the case-control association studies. All participants gave informed consent and the study was approved by the local ethics committees.

Phenotypic characterisation of the subjects. All laboratory specimens were taken after a $12-$ h overnight fast. Glucose tolerance was assessed by a 75-g oral glucose test. Type II diabetes and impaired glucose tolerance (IGT) were diagnosed according to the 1985 World Health Organization (WHO) criteria [28]. Hypertension was defined as blood pressure above $160 / 90 \mathrm{mmHg}$ or known treatment for hypertension or both. Blood pressure was measured with a sphygmomanometer with the subject in the sitting position after a rest for $15 \mathrm{~min}$ and the values are given as the average of two measurements within $10 \mathrm{~min}$. Waist was measured with a soft tape midway between the lowest rib and the iliac crest and the hip circumference at the widest part of the gluteal region. Patients were considered to have the metabolic syndrome if they had diabetes or IGT and fulfilled at least two of the following criteria: (1) waist to hip ratio more than 0.85 for women and more than 0.90 for men or BMI more than $30 \mathrm{~kg} / \mathrm{m}^{2}$ or both, (2) serum triglyceride concentration more than $1.7 \mathrm{mmol} / \mathrm{l}$ or HDL cholesterol concentration less than $1.0 \mathrm{mmol} / \mathrm{l}$ for women and less than $0.9 \mathrm{mmol} / \mathrm{l}$ for men, (3) hypertension (as defined above) or (4) microalbuminuria defined as more than $20 \mu \mathrm{g} / \mathrm{min}$ in an overnight urine collection [29]. Information about a history of stroke and myocardial infarction was obtained from a questionnaire filled in together with a trained nurse. Stroke included both ischaemic and haemorrhagic events requiring admission to hospital. Similarly, diagnosis of myocardial infarction was always established in the hospital.

Assays. Serum-free insulin concentrations, plasma glucose, serum HDL-cholesterol and triglycerides were measured as described earlier [27]. Urine albumin concentration was deter- 
Table 1. Characteristics of subjects in the genotype discordant sibling analysis according to the presence of the A1 (A1A1 genotype) or A2 (A1A2 and A2A2 genotypes) variant of the GYS1 XbaI polymorphism

\begin{tabular}{|c|c|c|c|c|c|c|c|c|c|}
\hline & \multicolumn{3}{|l|}{ All } & \multicolumn{3}{|l|}{ Men } & \multicolumn{3}{|l|}{ Women } \\
\hline & A1 variant & A2 variant & $p$ value & A1 variant & A2 variant & $p$ value & A1 variant & A2 variant & $p$ value \\
\hline$n$ & 84 & 93 & - & 30 & 29 & - & 54 & 64 & - \\
\hline Age (years) & $60 \pm 13$ & $61 \pm 12$ & 0.45 & $55 \pm 12$ & $55 \pm 10$ & 0.67 & $61 \pm 13$ & $63 \pm 13$ & 0.53 \\
\hline Body mass index $\left(\mathrm{kg} / \mathrm{m}^{2}\right)$ & $29.1 \pm 4.8$ & $29.4 \pm 4.4$ & 0.67 & $27.8 \pm 2.8$ & $28.8 \pm 3.9$ & 0.31 & $29.8 \pm 5.5$ & $29.6 \pm 4.5$ & 0.94 \\
\hline Fasting blood glucose (mmol/l) & $7.3 \pm 2.9$ & $7.3 \pm 2.9$ & 0.93 & $7.6 \pm 3.5$ & $8.0 \pm 3.9$ & 0.75 & $7.2 \pm 2.5$ & $7.0 \pm 2.2$ & 0.98 \\
\hline Fasting serum insulin $(\mathrm{mU} / \mathrm{l})$ & $14.3 \pm 13.4$ & $16.8 \pm 15.9$ & 0.36 & $14.3 \pm 15.7$ & $20.7 \pm 18.2$ & 0.14 & $14.4 \pm 12.1$ & $15.0 \pm 14.6$ & 0.92 \\
\hline Waist: hip ratio & $0.92 \pm 0.09$ & $0.93 \pm 0.08$ & 0.68 & $0.99 \pm 0.07$ & $0.99 \pm 0.07$ & 0.74 & $0.88 \pm 0.08$ & $0.90 \pm 0.07$ & 0.33 \\
\hline Systolic blood pressure (mm Hg) & $137 \pm 19$ & $141 \pm 20$ & 0.17 & $132 \pm 13$ & $142 \pm 23$ & 0.090 & $140 \pm 19$ & $141 \pm 18$ & 0.88 \\
\hline Diastolic blood pressure ( $\mathrm{mm} \mathrm{Hg}$ ) & $80 \pm 9$ & $81 \pm 11$ & 0.44 & $80 \pm 10$ & $84 \pm 14$ & 0.42 & $80 \pm 9$ & $80 \pm 9$ & 0.97 \\
\hline Triglycerides $(\mathrm{mmol} / \mathrm{l})$ & $1.5 \pm 0.8$ & $1.9 \pm 1.5$ & 0.084 & $1.7 \pm 1.0$ & $1.8 \pm 1.2$ & 0.73 & $1.5 \pm 0.6$ & $1.9 \pm 1.6$ & 0.066 \\
\hline HDL-cholesterol (mmol/l) & $1.2 \pm 0.3$ & $1.2 \pm 0.3$ & 0.61 & $1.1 \pm 0.2$ & $1.1 \pm 0.2$ & 0.62 & $1.2 \pm 0.3$ & $1.2 \pm 0.3$ & 0.72 \\
\hline Type II diabetes $(\%)$ & 64.3 & 68.8 & 0.52 & 66.7 & 69.0 & 0.85 & 63.0 & 68.8 & 0.51 \\
\hline Impaired glucose tolerance (\%) & 13.1 & 9.7 & 0.47 & 13.3 & 3.5 & 0.17 & 13.0 & 12.5 & 0.94 \\
\hline Hypertension (\%) & 48.2 & 63.4 & 0.042 & 37.9 & 69.0 & 0.018 & 53.7 & 60.9 & 0.43 \\
\hline Obesity (\%) & 34.5 & 46.7 & 0.10 & 23.3 & 41.4 & 0.14 & 40.7 & 49.2 & 0.36 \\
\hline Abdominal obesity (\%) & 72.6 & 75.8 & 0.63 & 90.0 & 82.8 & 0.42 & 63.0 & 72.6 & 0.27 \\
\hline Hypertriglyceridaemia (\%) & 30.1 & 44.0 & 0.056 & 27.6 & 41.4 & 0.27 & 31.5 & 45.3 & 0.16 \\
\hline Low HDL-cholesterol (\%) & 23.8 & 25.6 & 0.79 & 23.3 & 17.2 & 0.56 & 24.1 & 29.5 & 0.12 \\
\hline Microalbuminuria (\%) & 6.7 & 16.1 & 0.10 & 4.8 & 23.8 & 0.078 & 7.7 & 12.2 & 0.51 \\
\hline Metabolic syndrome (\%) & 42.3 & 57.7 & 0.13 & 47.1 & 52.9 & 0.50 & 39.7 & 60.3 & 0.16 \\
\hline Myocardial infarction (\%) & 8.3 & 11.1 & 0.53 & 6.7 & 31.0 & 0.016 & 9.3 & 3.1 & 0.16 \\
\hline Insulin treatment $(\%)$ & 23.3 & 39.4 & 0.053 & 23.8 & 60.0 & 0.019 & 23.1 & 30.4 & 0.45 \\
\hline Anti-hypertensive treatment (\%) & 40.4 & 59.1 & 0.013 & 33.3 & 65.5 & 0.013 & 44.4 & 56.3 & 0.20 \\
\hline
\end{tabular}

Data is given as means \pm standard deviation or as percentage and is compared between subjects with the A1 variant vs those with the A2 variant. Definitions of the different characteristics of the metabolic syndrome and of the metabolic syndrome are described under methods. Information about albumin excrea- tion rate was available only for 122 subjects ( 42 men and 80 women 60 with the A1 variant and 62 with the A2 variant) and the given percentage is calculated from these subjects. Frequency of insulin treatment is calculated from diabetic patients only mined with radioimmunoassay with a detection limit of $2 \mathrm{mg} / \mathrm{l}$ and an interassay coefficient of variation of $5 \%$. The homeostasis model assessment (HOMA) index (fasting serum insulin times fasting plasma glucose divided by 22.5) was used to estimate the degree of insulin resistance [30].

Genotyping. The XbaI polymorphism in intron 14 of the GYS1 gene was genotyped using the earlier described PCR method [17]. The 579 bp amplification product was digested with $\mathrm{XbaI}$ restriction enzyme (Amersham, Pharmacia Biotech, Solna, Sweden) according to manufacturers' instructions and the digestion products were separated on an agarose gel. The wildtype allele (allele A1) is not digested whereas the A2 allele is seen as two bands of $483 \mathrm{bp}$ and $96 \mathrm{bp}$. Samples with one or two A2 alleles were analysed twice to exclude genotyping errors. The definitions "A1 variant" (genotype A1A1) and "A2 variant" (genotypes A1A2 and A2A2) are used throughout the text.

Sequencing analysis of intron 14 of the GYS1 gene. The genomic fragment containing the whole intron 14 (690 bp) of the GYS1 was amplified using oligonucleotide primers in exons 14 and 15. This DNA fragment was isolated from an agarose gel, column purified and sequenced bidirectionally using Thermo Sequenase dye termination cycle sequencing pre mix kit (Amersham) and automated sequencing analysis (ABI, model 373; Perkin Elmer, La Jolla, Calif., USA). Sequencing analysis of intron 14 was done in 6 subjects, two of each genotype (A1A1, A1A2, A2A2). The intron 14 sequences were further analysed using a MatInspector V2.2 program for identification of potential sequence motifs [31].

Statistical analyses. Values are given as means \pm standard deviation. The significance of differences between the clinical characteristics were tested by Student's $t$ test or by the Mann-Whitney test statistics if the variable was not normally distributed.
Frequency differences were tested by Pearson chi-square test. Since our previous association studies have indicated that the XbaI polymorphism in the GYS1 gene identifies a subgroup of patients with Type II diabetes characterised by a strong family history of Type II diabetes, a high prevalence of hypertension and insulin resistance, we hypothesised that the phenotypic differences between the sib-pairs discordant for this polymorphism, would differ significantly from zero. Because 51 siblings were shared by more than one pair creating a non-independence between the pairs, the following two statistical methods were used to compute the differences between the sibpairs: (1) McNemar test of symmetry for paired replicates for 65 randomly chosen pairs (one pair of each sex per sibship from the 122 pairs was chosen using a randomisation program) to test differences in categorical variables of the metabolic syndrome, in macrovascular complications or in medication. If McNemar expected frequency was less than 5, a binomial test was used instead and the probability was estimated using a two-tailed test [32]; (2) The differences in continuous variables between the siblings were estimated using a permutation test for paired replicates [33]. The permutation test does not make any assumptions about the normality, homogeneity of the variance or the precise form of the underlying distribution. In the permutation test for 122 pairs there are $2^{122}$ equally likely outcomes for each variable under the assumption of no difference between the paired siblings. Because of computational limitations, the two-tailed $p$ values were estimated using a very large $\left(10^{7}\right)$ random sample from all the possible permutations. If the observed sum of differences (OSD) entered into the $5 \%$ region of rejection, the difference between pairs was considered significant. The differences in phenotypic values were computed as the value in the sibling with the A2 variant minus the value in the sibling with the A1 variant. For all the analyses except for the permutation test, the BMDP Statistical Software version 1.12 (Los Angeles, Calif.,USA) was used. The simulation 
program for the permutation test was based on a program described previously [33] and modified by T. Kanninen. All statistical tests were two-sided and a $p$ value less than 0.05 was considered statistically significant.

\section{Results}

Clinical characteristics of Type II diabetic patients in the case-control association study. Allele frequencies differed between 216 randomly chosen unrelated Type II diabetic patients and 115 unrelated healthy control spouses without a family history of Type II diabetes $(12.7$ vs $6.5 \%, p=0.013)$. Genotype frequencies were in the Hardy-Weinberg equilibrium and differed significantly between Type II diabetic patients and healthy control spouses $(75.9 \%, 22.7 \%$ and $1.4 \%$ vs $87.0 \%, 13.0 \%$ and $0 \%, p=0.042$ ). Type II diabetic patients with the A2 variant had lower HDL-cholesterol concentrations $(p=0.035)$ and higher HOMA estimates of insulin resistance $(p=0.0023)$ than patients with the $\mathrm{A} 1$ variant (Table 2). In addition, they were more often treated with insulin $(p=0.011)$. Male patients with the A2 variant had higher BMI $(30.7 \pm 3.6$ vs $28.4 \pm 4.2 \mathrm{~kg} /$ $\left.\mathrm{m}^{2}, p=0.019\right)$, higher frequency of anti-hypertensive medication ( 70.8 vs $42.0 \%, p=0.015)$, and they reported more often a history of myocardial infarction (37.5 vs $13.2 \%, p=0.010$ ) than male patients with the A1 variant. No difference was seen between control subjects with $(n=15)$ and without $(n=100)$ the A2 variant of the XbaI polymorphism with respect to these variables.

Clinical characteristics of subjects in the genotype discordant sibling analysis. Altogether 175 subjects out of the 743 siblings screened for the GYS1 XbaI polymorphism were found to be carriers of the A2 variant $(23.6 \%)$. The A2 allele frequency was similar between men and women $(12.1 \%$ and $11.9 \%)$ and did not statistically significantly differ between siblings with normal $(11.5 \%)$, impaired $(13.0 \%)$ or diabetic $(12.0 \%)$ glucose tolerance. In total 93 subjects ( 29 men and 64 women) carrying the A2 allele had at least one sibling of the same sex who was discordant for the XbaI polymorphism yielding a total of 122 discordant sibling pairs (38 male and 84 female pairs, 59 men and 118 women). Only two subjects were homozygous for the XbaI polymorphism. Table 1 illustrates the clinical characteristics of the 177 subjects according to presence or absence of the A2 variant. Subjects with the A2 variant had more hypertension $(p=0.042)$ and were more often treated with anti-hypertensive drugs $(p=0.013)$ than subjects with the A1 variant. These differences were particularly pronounced among the male subjects with the A 2 variant $(p=0.018$ and $p=0.013)$ (Table 1$)$. The male siblings with the A2 variant reported more often
Table 2. Clinical characteristics of Type II diabetic patients in the case-control association study according to the presence of the $\mathrm{A} 1$ or the $\mathrm{A} 2$ variant of the GYS1 XbaI polymorphism

\begin{tabular}{|c|c|c|c|}
\hline & A1 variant & A2 variant & $p$ value \\
\hline$\overline{n(\mathrm{men} / \text { women })}$ & $69 / 95$ & $24 / 28$ & - \\
\hline Age (years) & $59 \pm 13$ & $61 \pm 14$ & 0.42 \\
\hline Age at onset (years) & $49 \pm 14$ & $52 \pm 12$ & 0.40 \\
\hline Body mass index $\left(\mathrm{kg} / \mathrm{m}^{2}\right)$ & $29.2 \pm 4.8$ & $30.4 \pm 4.4$ & 0.10 \\
\hline $\begin{array}{l}\text { Fasting blood glucose } \\
(\mathrm{mmol} / \mathrm{l})\end{array}$ & $8.7 \pm 2.9$ & $9.5 \pm 3.4$ & 0.15 \\
\hline $\begin{array}{l}\text { Fasting serum insulin } \\
(\mathrm{mU} / \mathrm{l})\end{array}$ & $15.8 \pm 13.5$ & $23.9 \pm 19.5$ & 0.0012 \\
\hline $\begin{array}{l}\text { HOMA-index for insulin } \\
\text { resistance }\end{array}$ & $7.5 \pm 8.4$ & $12.0 \pm 11.5$ & 0.0023 \\
\hline Waist: hip ratio & $0.93 \pm 0.11$ & $0.96 \pm 0.09$ & 0.10 \\
\hline $\begin{array}{l}\text { Systolic blood pressure } \\
(\mathrm{mm} \mathrm{Hg})\end{array}$ & $142 \pm 21$ & $140 \pm 21$ & 0.63 \\
\hline $\begin{array}{l}\text { Diastolic blood pressure } \\
(\mathrm{mm} \mathrm{Hg})\end{array}$ & $81 \pm 11$ & $79 \pm 12$ & 0.28 \\
\hline Triglycerides (mmol/l) & $1.8 \pm 1.2$ & $2.2 \pm 2.2$ & 0.26 \\
\hline HDL-cholesterol (mmol/l) & $1.2 \pm 0.4$ & $1.1 \pm 0.3$ & 0.035 \\
\hline Hypertension (\%) & 59.5 & 65.4 & 0.45 \\
\hline Obesity (\%) & 38.9 & 53.9 & 0.058 \\
\hline Abdominal obesity (\%) & 80.3 & 86.5 & 0.31 \\
\hline Hypertriglyceridaemia (\%) & 40.1 & 44.2 & 0.60 \\
\hline Low HDL-cholesterol (\%) & 22.0 & 31.3 & 0.19 \\
\hline Microalbuminuria (\%) & 13.5 & 18.0 & 0.49 \\
\hline The metabolic syndrome (\%) & 71.8 & 78.9 & 0.32 \\
\hline Myocardial infarction (\%) & 11.7 & 21.2 & 0.089 \\
\hline Insulin treatment $(\%)$ & 28.8 & 48.1 & 0.011 \\
\hline $\begin{array}{l}\text { Anti-hypertensive treatment } \\
(\%)\end{array}$ & 51.2 & 61.5 & 0.19 \\
\hline
\end{tabular}

Data is given as means \pm standard deviation or as percentage. Definitions of the different characteristics of the metabolic syndrome and of the metabolic syndrome are described under methods. Fasting insulin in Type II diabetic patients without insulin treatment was $11.0 \pm 6.3 \mathrm{mU} / \mathrm{l}$ (A1 variant) and $13.8 \mathrm{mU} / \mathrm{l}$ (A2 variant) $(p=0.15)$. HOMA-index in Type II diabetic patients without insulin treatment was $4.6 \pm 3.2$ (A1 variant) and $5.8 \pm 4.0$ (A2 variant) $(p=0.12)$. Information about the albumin excreation rate was available only for 158 Type II diabetic patients (119 with the A1 and 39 with the A2 variant) and the given percentages are calculated from these subjects

a history of myocardial infarction compared with siblings with the A1 variant $(p=0.016)$. Diabetic male patients with the A2 variant were also significantly more often treated with insulin compared with men with the A1 variant $(p=0.017)$.

Differences between siblings discordant for the XbaI polymorphism. In contrast to the presentation above, which compared means between groups of siblings with or without the A2 variant of the XbaI polymorphism, we here present differences between individual sibling pairs discordant for the XbaI polymor- 
Table 3. McNemar test of symmetry for occurrence of features of the metabolic syndrome, macrovascular complications and treatment within sib-pairs discordant for the GYS1 XbaI polymorphism

\begin{tabular}{|c|c|c|c|c|c|c|c|c|c|}
\hline & \multicolumn{3}{|c|}{ All pairs $(n=65)$} & \multicolumn{3}{|c|}{ Male pairs $(n=22)$} & \multicolumn{3}{|c|}{ Female pairs $(n=43)$} \\
\hline & A1 variant & A2 variant & $p$ value & A1 variant & A2 variant & $p$ value & A1 variant & A2 variant & $p$ value \\
\hline Age (years) & $60 \pm 14$ & $60 \pm 12$ & 0.57 & $56 \pm 13$ & $55 \pm 11$ & 0.54 & $61 \pm 14$ & $63 \pm 13$ & 0.23 \\
\hline Type II diabetes or IGT & $15(55.6)$ & $12(44.4)$ & 0.56 & $5(62.5)$ & $3(37.5)$ & 0.48 & $10(52.6)$ & $9(47.4)$ & 0.82 \\
\hline Hypertension & $5(21.7)$ & $18(78.3)$ & 0.0067 & $1(10.0)$ & $9(90.0)$ & 0.011 & $4(30.8)$ & $9(69.2)$ & 0.17 \\
\hline Obesity & $6(27.3)$ & $16(72.7)$ & 0.033 & $3(37.5)$ & $5(62.5)$ & 0.48 & $3(21.4)$ & $11(78.6)$ & 0.033 \\
\hline Abdominal obesity & $10(43.5)$ & $13(56.5)$ & 0.53 & $3(75.0)$ & $1(25.0)$ & 0.32 & $7(36.8)$ & $12(63.2)$ & 0.25 \\
\hline Microalbuminuria & $0(0.0)$ & $6(100.0)$ & 0.031 & $0(0.0)$ & $2(100.0)$ & 0.50 & $0(0.0)$ & $4(100.0)$ & 0.13 \\
\hline The metabolic syndrome & $11(34.4)$ & $21(65.6)$ & 0.077 & $4(44.4)$ & $5(55.6)$ & 0.74 & $7(30.4)$ & $16(69.6)$ & 0.061 \\
\hline Myocardial infarction & $4(33.3)$ & $8(66.7)$ & 0.25 & $1(12.5)$ & $7(87.5)$ & 0.070 & $3(75.0)$ & $1(25.0)$ & 0.63 \\
\hline Stroke & $4(40.0)$ & $6(60.0)$ & 0.75 & $2(50.0)$ & $2(50.0)$ & 1.0 & $2(33.3)$ & $4(66.7)$ & 0.69 \\
\hline Insulin treatment & $8(30.8)$ & $18(69.2)$ & 0.050 & $1(11.1)$ & $8(88.9)$ & 0.039 & $7(41.2)$ & $10(58.8)$ & 0.47 \\
\hline Anti-hypertensive treatment & $6(23.1)$ & $20(76.9)$ & 0.0060 & $2(16.7)$ & $10(83.3)$ & 0.021 & $4(28.6)$ & $10(71.4)$ & 0.109 \\
\hline
\end{tabular}

Age is means \pm standard deviation. Only the $n(\%)$ of pairs discordant for the particular phenotype or treatment are shown. The A1 variant column shows the $n$ (\%) of pairs where the sibling with the A1 variant has the phenotype or treatment in question whereas the paired sibling with the A2 variant does not and the A2 variant column shows the opposite situation.
Sixty-five randomly chosen pairs from 65 sibships were analysed pairwise by McNemar test. When the McNemar frequency was less than $5, p$ values were calculated by a binomial test. Definitions of the different characteristics of the metabolic syndrome and of the metabolic syndrome are described under methods phism. Within each sib-pair the siblings having the A2 variant had more hypertension $(p=0.0067)$, obesity $(p=0.033)$ and microalbuminuria $(p=0.031),(\mathrm{Ta}-$ ble 3). The difference in occurrence of hypertension was particularly seen between male sib-pairs $(p=0.011)$, whereas obesity was more common in female siblings with the A2 variant $(p=0.033)$ (Table 3$)$. The siblings with the A2 variant were more often treated with insulin $(p=0.050)$ or anti-hypertensive medication $(p=0.0060)$ or both (Table 3$)$.

Phenotypic differences within the sib-pairs were further specified by permutation test; among the 122 sib-pairs, siblings carrying the A2 variant had higher triglycerides $(p=0.028)$ (Table 4$)$. This was particularly seen among female sib-pairs (OSD $26.7 \mathrm{mmol} / \mathrm{l}$, $p=0.017)$ and within the sib-pairs with Type II diabetes $(p=0.023)$ (Table 4). The diabetic siblings with the A2 variant also had lower HDL-cholesterol concentrations $(p=0.0059)$ and an earlier age at onset of diabetes $(p=0.022)$ than the diabetic A1 variant carriers (Table 4$)$. The siblings with the A2 variant had higher fasting serum insulin values $(p=0.018)$. The lower fasting blood glucose concentrations $(p=0.044)$ in the diabetic siblings with the A2 compared with the A1 variant is most likely explained by more frequent insulin therapy. Male siblings with the A2 variant had higher systolic (OSD $401.0 \mathrm{mmHg}$, $p=0.010$ ) and diastolic (OSD $260.5 \mathrm{mmHg}$, $p=0.022$ ) blood pressure compared with their sibpairs with the A1 variant. This difference was seen despite the A2 carriers having had more antihypertensive treatment. Systolic and particularly diastolic blood pressure values were also higher among nondiabetic siblings carrying the A2 variant $(p=0.067$ and $p=0.0014$, respectively) compared with non-diabetic siblings with the A1 variant (Table 4).

Sequencing analysis of intron 14 of the GYS1 gene. Sequencing the whole intron 14, which contains the polymorphic XbaI site did not show any further sequence variations in diabetic subjects with one or more A2 alleles. Neither did the MatInspector V2.2 program detect any changes in potential regulatory motifs between the intron 14 sequence from patients with or without the A2 variant.

\section{Discussion}

This study using a paired-sibling-approach confirmed our previous findings of an association between the XbaI polymorphism and features of the metabolic syndrome in a population-based study $[12,17]$. These features included obesity, hypertension, hypertriglyceridaemia, low HDL cholesterol concentrations and microalbuminuria. Importantly, as the metabolic syndrome has been considered a risk factor for cardiovascular disease, men with the A2 variant reported a higher frequency of myocardial infarction than males with the A1 variant both in the case-control and in the genotype-discordant sibling analysis. The metabolic syndrome [26] and its components including hypertension have been shown to predict and precede Type II diabetes. In support of this view, diabetic siblings with the A2 variant had an earlier onset of diabetes than diabetic siblings with the A1 variant. Although the frequency of the A2 allele was higher among Type II diabetic patients than among the con- 
Table 4. Differences in clinical characteristics of siblings discordant for the GYS1 XbaI polymorphism analysed by permutation test

\begin{tabular}{|c|c|c|c|c|c|c|}
\hline & \multicolumn{2}{|c|}{ All pairs $n=122$} & \multicolumn{2}{|c|}{ Type II diabetic pairs $n=52$} & \multicolumn{2}{|c|}{ Non-diabetic pairs $n=15$} \\
\hline & $\begin{array}{l}\text { Observed sum } \\
\text { of differences }\end{array}$ & $p$ value & $\begin{array}{l}\text { Observed sum } \\
\text { of differences }\end{array}$ & $p$ value & $\begin{array}{l}\text { Observed sum } \\
\text { of differences }\end{array}$ & $p$ value \\
\hline Age at onset of Type II diabetes (years) & - & - & -223.0 & 0.022 & - & - \\
\hline Body mass index $\left(\mathrm{kg} / \mathrm{m}^{2}\right)$ & -14.0 & 0.81 & -9.7 & 0.77 & -11.6 & 0.64 \\
\hline Fasting blood glucose (mmol/l) & -14.3 & 0.72 & -42.0 & 0.044 & 0.5 & 0.83 \\
\hline Fasting serum insulin (mU/1) & 339.1 & 0.018 & 192.6 & 0.083 & -43.5 & 0.061 \\
\hline Systolic blood pressure $(\mathrm{mm} \mathrm{Hg})$ & 447.5 & 0.10 & 198.0 & 0.28 & 153.0 & 0.067 \\
\hline Diastolic blood pressure (mm Hg) & 271.0 & 0.075 & 102.0 & 0.30 & 139.5 & 0.0014 \\
\hline Triglycerides $(\mathrm{mmol} / \mathrm{l})$ & 31.8 & 0.028 & 26.3 & 0.023 & 0.94 & 0.76 \\
\hline HDL-cholesterol (mmol/l) & -3.4 & 0.36 & -7.1 & 0.0059 & 2.9 & 0.043 \\
\hline
\end{tabular}

Observed sum of differences is the sum of differences calculated as the value in sibling with the $\mathrm{A} 2$ variant minus the value in sibling with the A1 variant. Two-tailed $p$ values were estimated from a large random sample $\left(10^{7}\right)$ of all possible permutations (for all pairs and pairs with Type II diabetes) or from the actual number of all possible permutations (for non-diabetic pairs) as described under methods. Observed sum of differences for fasting blood glucose, fasting serum insulin and the HOMA-index in Type II diabetic pairs that were not on insulin treatment $(n=24)$ were $-13.6 \mathrm{mmol} / \mathrm{l} \quad(p=0.28), 1.8 \mathrm{mU} / \mathrm{l}$ $(p=0.95)$ and $9.5(p=0.47)$, respectively trol subjects, siblings with the A2 variant did not have a higher frequency of diabetes than siblings with the A1 variant. It should, however, be kept in mind that diabetes is not the ultimate end-point of the metabolic syndrome. For the manifestation of diabetes, impaired beta-cell function is also required. The metabolic syndrome is possibly a stronger predictor of cardiovascular disease than of diabetes.

Some of the features of the metabolic syndrome are gender-specific, i.e. waist-to-hip ratio, HDL-cholesterol and triglycerides. In addition, the prevalence of myocardial infarction differs considerably between men and women. Genetic influences may therefore differ between the sexes, which has been shown for, e.g. the $\beta_{3}$-adrenergic receptor gene [24]. We therefore considered it important to analyse data separately for men and women. Since we have tested the influence of the A2 allele of the XbaI polymorphism on several features of the metabolic syndrome, one could argue that we should adjust for multiple comparisons. Most of the features of the metabolic syndrome are strongly interrelated and under such circumstances an adjustment for multiple comparisons would be overly conservative.

Although several authors have reported an association between polymorphisms in the GYS1 gene and Type II diabetes [12-16], a number of negative studies have been published [18-20]. These discrepant results highlight the problems with populationbased association studies. Differences in the genetic background (other than the GYS1 gene) between patients and control subjects can contribute to a false positive or negative result.

How would the XbaI polymorphism confer increased susceptibility to the metabolic syndrome or Type II diabetes or both? Mutation screening and in vitro studies have not been able to identify common pathogenic mutations in the coding regions of GYS1 $[15,16,19,34]$. The XbaI polymorphism does not seem to create or remove any regulatory sequence motif in intron 14, indicating that the polymorphism by itself is not a functional variant. Earlier studies have indicated that the basal expression of GYS1 mRNA is either normal [15,35] or decreased [36] in patients with Type II diabetes whereas protein levels have been reported to be either normal [36], decreased [15] or increased [35]. The regulation of GYS1 expression is not well understood and it is possible that quantitative differences in different studies could be because patients were studied at different metabolic stages.

It is thus more likely that the XbaI polymorphism is in linkage disequilibrium with another gene in the region. Support for this view comes from a French study showing a statistically significant association between the XbaI polymorphism and Type II diabetes [13]. The A2 variant was, however, decreased and not increased in the French diabetic patients, which is compatible with the concept of linkage disequilibrium and further challenges the XbaI polymorphism itself as the cause of these associations. More than 30 genes have been mapped to the $19 \mathrm{q} 13.3$ region $[37,38]$, including genes for vasodilator stimulated phosphoprotein $(V A S P)$, protein phosphatase 5 catalytic subunit (PPP5C), dystrophia myotonica associated homeodomain protein $(D M A H P)$, calmodulin 3 (CALM3), histidine rich calcium binding protein $(H R C)$ and two Shaker related potassium voltage gated channels (KCNA7 and KCNC3). The KCNA7 gene was recently located between GYS1 and HRC, within $50 \mathrm{~kb}$ from GYS1 [39]. In addition, we have recently found an association between the hormone 
sensitive lipase gene (HSL) and Type II diabetes and abdominal obesity in population association and intra-family association studies [40]. HSL is located on chromosome $19 \mathrm{q} 13.2$, about $10 \mathrm{Mb}$ centromeric to GYS1 and can thus hardly be responsible for the findings of the present study.

In conclusion, a paired-sibling design was used to study the phenotype associated with the A2 variant of the GYS1 XbaI polymorphism in families with Type II diabetes. In non-diabetic siblings the presence of the A2 variant was associated with high blood pressure and in patients with Type II diabetes with earlier age at onset of diabetes and with characteristics of the metabolic syndrome.

Acknowledgements. We are indebted to the patients for their participation and to Ms. M. Åberg for excellent technical assistance. This work was supported by grants from the Sigrid Juselius Foundation (L.C. Groop), the Albert Påhlssons Foundation (M.Orho-Melander), the Swedish Medical Research Council (L. C. Groop and M. Orho-Melander), Medical Faculty of Lund University, Malmö University Hospital, the Ernhold Lundström Foundation, the Diabetes Association in Malmö, the Anna-Lisa and Sven-Eric Lundgren Foundation for Medical Research, the Royal Physiographical Society in Lund (all to M. Orho-Melander), Novo Nordic Foundation (L. C. Groop), the Juvenile Diabetes Foundation International (JDF) (L.C.Groop), and an EEC-grant BMH4-CT95-0662 (L. C. Groop).

\section{References}

1. Eriksson J, Franssila-Kallunki A, Ekstrand A et al. (1989) Early metabolic defects in persons at increased risk for non-insulin-dependent diabetes mellitus. N Engl J Med 321: 337-343

2. Warram J, Martin B, Krolewski A, Soeldner J, Kahn R (1990) Slow glucose removal rate and hyperinsulinemia precede the development of type II diabetes in offspring of diabetic parents. Ann Intern Med 113: 909-915

3. Shulman GI, Rothman DL, Jue T, Stein P, DeFronzo RA (1990) Quantitation of muscle glycogen synthesis in normal subjects and subjects with non-insulin-dependent diabetes by ${ }^{13} \mathrm{C}$ nuclear magnetic resonance spectroscopy. $\mathrm{N}$ Engl $\mathrm{J}$ Med 322: 223-228

4. Schalin-Jäntti C, Härkönen M, Groop L (1992) Impaired activation of glycogen synthase in people at increased risk for developing NIDDM. Diabetes 41: 598-604

5. Vaag A, Henriksen J, Beck-Nielsen H (1992) Decreased activation of glycogen synthase in skeletal muscle of young nonobese Caucasian first-degree relatives of patients with non-insulin-dependent diabetes mellitus. J Clin Invest 89: 782-788

6. Thorburn AW, Gumbiner B, Bulacan R, Brechtel G, Henry RR (1991) Multiple defects in muscle glycogen synthase activity contribute to reduced glycogen synthesis in non-insulin dependent diabetes mellitus. J Clin Invest 87: 489-495

7. Wells A, Sutcliffe I, Johnson A, Taylor R (1993) Abnormal activation of glycogen synthase in fibroblasts from NIDDM patients. Evidence for an abnormality specific to glucose metabolism. Diabetes 42: 583-589

8. Henry RR, Ciaraldi TP, Abrams-Carter L, Mudaliar S, Park KS, Nikoulina SE (1996) Glycogen synthase activity is reduced in cultured skeletal muscle cells of non-insulindependent diabetes mellitus subjects. Biochemical and molecular mechanisms. J Clin Invest 98: 1231-1236

9. Perseghin G, Price TB, Petersen KF et al. (1996) Increased glucose transport-phosphorylation and muscle glycogen synthesis after exercise training in insulin-resistant subjects. N Engl J Med 335: 1357-1362

10. Manchester J, Skurat A, Roach P, Haushaka S, Lawrence J (1996) Increased glycogen accumulation in transgenic mice overexpressing glycogen synthase in skeletal muscle. Proc Natl Acad Sci U S A 93: 10707-10711

11. Lehto M, Stoffel M, Groop L, Espinosa RD, Le Beau MM, Bell GI (1993) Assignment of the gene encoding glycogen synthase (GYS) to human chromosome 19, band q13.3. Genomics 15 (2):460-461

12. Groop LC, Kankuri M, Schalin-Jäntti C et al. (1993) Association between polymorphism of the glycogen synthase gene and non-insulin-dependent diabetes. N Engl J Med 328: $10-14$

13. Zouali H, Velho G, Froguel P (1993) Polymorphism of the glycogen synthase gene and non-insulin-dependent diabetes mellitus (letter). N Engl J Med 328: 1568

14. Kuroyama H, Sanke T, Ohagi S, Furuta M, Furuta H, Nanjo K (1994) Simple tandem repeat in the human muscle glycogen synthase gene is associated with NIDDM in Japanese subjects. Diabetologia 37: 536-539

15. Majer M, Mott DM, Mochizuki H et al. (1996) Association of the glycogen synthase locus on 19q13 with NIDDM in Pima Indians. Diabetologia 39: 314-321

16. Shimomura H, Sanke T, Ueda K, Hanabusa T, Sakagashira S, Nanjo K (1997) A missense mutation of the muscle glycogen synthase gene $(\mathrm{M} 416 \mathrm{~V})$ is associated with insulin resistance in Japanese population. Diabetologia 40: 947-952

17. Schalin-Jäntti C, Nikula-Ijäs P, Huang X et al. (1996) Polymorphism of the glycogen synthase gene in hypertensive and normotensive subjects. Hypertension 27: 67-71

18. Kadowaki T, Kadowaki H, Yazaki Y (1993) Polymorphism of the glycogen synthase gene and non-insulin-dependent diabetes mellitus (letter). N Engl J Med 328: 1568-1569

19. Rissanen J, Pihlajamäki J, Heikkinen S et al. (1997) New variants in the glycogen synthase gene (Gln71His, Met416Val) in patients with NIDDM from eastern Finland. Diabetologia 40: 1313-1319

20. Elbein SC, Hoffman M, Ridinger D et al. (1994) Description of a second microsatellite marker and linkage analysis of the muscle glycogen synthase locus in familial NIDDM. Diabetes 43: 1061-1065

21. Lander E, Schork N (1994) Genetic dissection of complex traits. Science 265: 2037-2048

22. Altshuler D, Kruglyak L, Lander E (1998) Genetic polymorphisms and a disease (letter). New Engl J Med 28: 1626

23. Curtis D (1997) Use of siblings as controls in case-control association studies. Ann Hum Genet 61: 319-333

24. Widen E, Lehto M, Kanninen Tet al. (1995) Association of a polymorphism in the $\beta$-adrenergic receptor gene with features of insulin resistance syndrome in Finns. New Engl J Med 333: 348-351

25. Mitchell B, Blangero J, Comuzzie A et al. (1998) A paired sibling analysis of the beta-3-adrenergic receptor and obesity in Mexican Americans. J Clin Invest 101: 584-587

26. Reaven GM (1988) Role of insulin resistance in human disease. Diabetes 37: 1595-1607

27. Groop L, Forsblom C, Lehtovirta M et al. (1996) Metabolic consequences of a family history of NIDDM (The Botnia study). Diabetes 45: 1585-1593 
28. World Health Organization Study Group on Diabetes Mellitus (1985) Technical Reports Series No. 727 WHO, Geneva

29. Alberti KGMM, Zimmet PZ, for the WHO Consultation (1998) Definition, diagnosis and classification of diabetes mellitus and its complications. Diabet Med 15: 539-553

30. Matthews DR, Hosker JP, Rudenski AS, Naylor BA, Treacher DF, Turner RC (1985) Homeostasis model assessment:insulin resistance and $\beta$-cell function from fasting plasma glucose and insulin concentrations in man. Diabetologia 28: 412-419

31. Quandt K, Frech K, Karas H et al. (1995) MatInd and MatInspector:new fast and versatile tools for detection of consensus matches in nucleotide sequence. Nucleic Acids Res 11: $4878-4884$

32. Sidney S, Castellan NJ Jr (1988) The McNemar change test. In: Nonparametric statistics for the behavioral sciences. The case of one sample, two measures or paired replicates. McGraw-Hill International Editions, Statistical Series, 2nd edn, McGraw-Hill Book Co., Singapore 5: 75-80

33. Sidney S, Castellan NJ Jr (1988) The permutation test for paired replicates. In: Nonparametric statistics for the behavioral sciences. The case of one sample, two measures or paired replicates. McGraw-Hill International Editions, Statistical Series, 2nd edn, McGraw-Hill Book Co., Singapore 5: 95-101
34. Orho M, Nikula-Ijäs P, Schalin-Jäntti C, Permutt MA, Groop LC (1995) Isolation and characterization of the human muscle glycogen synthase gene. Diabetes 44: 1099-1105

35. Löfman M, Yki-Järvinen H, Parkkonen M et al. (1995) Increased concentrations of glycogen synthase protein in skeletal muscle of patients with NIDDM. Am J Physiol 269: E27-E32

36. Vestergaard H, Lund S, Larsen FS et al. (1993) Glycogen synthase and phosphofructokinase protein and mRNA levels in skeletal muscle from insulin-resistant patients with non-insulin-dependent diabetes mellitus. J Clin Invest 91: 2342-2350

37. Ashworth L, Batzer M, Brandriff B et al. (1995) An integrated physical map of human chromosome 19. Nat Genet 11: $422-427$

38. http://www-bio.llnl.gov/genome/html/gene_ideogram.html (1998) LLNL Gene Ideogram for human chromosome 19

39. Kalman K, Nguyen A, Yseng-Crank J et al. (1998) Genomic organization, chromosomal localization, tissue distribution, and biophysical characterization of a novel mammalian shaker-related voltage gated potassium channel, Kv1.7. J Biol Chem 273: 5851-5857

40. Klannemark M, Orho M, Langin D et al. (1998) The putative role of the hormone sensitive lipase gene in the pathogenesis of Type II diabetes mellitus and abdominal obesity. Diabetologia 41: 1516-1522 